R. Historia, São Paulo, 120, p.85-96,jan/jul. 1989.

\title{
SER MÃE: A ESCRAVA EM FACE DO ABORTO E DO INFANTICIDIO*
}

\author{
Maria Lucia de Barros Morr**
}

RESUMO: A autora documenta através de fontes secundárias e da literatura dos viajantes, a presença da criança escrava, estimada em cerca de 1 a $20 \%$ do total da população escrava, reconstituindo os ciclos da infância e as tarefas desempenhadas por crias entre 7 e 12 anos de idade. As marcas deixadas pelas atividades exercidas desde tenra idade, as escolas para ensinar crianças, a exploração das mães como amas de leite, confirmando o seu relativo valor econômico. Finalmente, discute sob novo prisma, a prática do aborto como estratégia de resistência contra os senhores.

UNITERMOS: escravidão, moleques, crias, trabalho infantil, aborto, infanticidio.

Esta reflexão, minha e pessoal, é uma tentativa de diálogo com alguns autores que têm produzido recentemente trabalhos sobre a família escrava e a reprodução da população escrava no Brasil, bem como com autores que têm apresentado o aborto e o infanticidio como formas de resistência escrava, e, sobretudo, com aqueles autores que têm questionado o caráter de resistência de tais práticas. Meu objetivo não é o de pontuar, mas o de levantar algumas questões para que juntos possamos repensar o nosso objeto de estudo.

Várias razões têm sido apontadas para a baixa reprodução da população escrava no Brasil: a maior proporção de homens do que de mulheres escravas, principalmente nas regiões voltadas para a economia de expor-

* Este artigo é resultado de uma pesquisa sobre a criança escrava que desenvolvi, juntamente com Renato Pinto Venâncio e Maria de Fátima Neves, no Centro de Demografía Histórica da América Latina - CEDHAL, sediado na Universidade de São Paulo.

** Pós-graduandado Departamento de História-FFLCH/USP. 
MOTT, Maria Lucie de Barros. Ser mãe: a escrava em face do aborto e do infanticídio.

tação; a facilidade em se obter escravos, por cerca de três séculos no mercado africano; o excesso de trabalho e os maus tratos infringidos às escravas durante a gravidez; o pequeno interesse do proprietário em investir na gravidez, parto e puerpério das escravas, e na criação das crias até que estivessem em idade produtiva; a alta taxa de mortalidade infantil; e as práticas contraceptivas utilizadas pelas escravas, como também o aborto e o infanticidio.

Para Jacob Gorender, "no regime escravista a criação dos filhos das escravas constitui um ônus para o senhor, É ele quem fornece os meios alimentos, vestuário, habitação, etc. - para que os Filhos das escravas se desenvolvam em idade adulta. Cada filho de escrava representa, por conseguinte, um acréscimo de despesa de resultados aleatórios, É certo que se tudo corresse favoravelmente, ao fim de 16 anos disporia o plantador de um escravo novo, apto para o trabalho em sua plenitude" 1 .

Relendo o relato de religiosos, cirurgiões e tripulantes dos navios negreiros, de viajantes que estiveram no Brasil no século XIX, bem como trabalhos de historiadores que estudaram o tráfico de escravos, encontramos sempre referências sobre as crianças transportadas.

Segundo o irmão Carli, citado por Kátia Mattoso, as crianças apinhavam-se na primeira ponte dos negreiros, como arenques num barril ${ }^{2}$. James Bardot, que foi para o Congo num navio inglês, em 1700, criticava os portugueses pela maneira que faziam o transporte, amontoando 650 a 700 escravos em cada barco: "os homens ficavam em pé, atados em estacas no porão; as mulheres sem crianças, entre os conveses, e aquelas que levavam crianças, na cabine grande; e as crianças ficavam na cabine do leme, o que no clima quente ocasionava um fedor intolerável" ${ }^{3}$,

A venda de crianças escravas récem desembarcadas, seja nos mercados de escravos, seja clandestinamente, quando o tráfico internacional foi proibido, encontra-se documentada na obra de inúmeros estrangeiros que estiveram no país, na primeira metade do século passado. Ebel, natural de Riga, que visitou o Rio de Janeiro em 1824, em uma de suas cartas escreveu sobre o grande número de crianças africanas vendidas no Valongo: "há dias fundeou um (negreiro) com 250 negros, na maioria crianças entre 10 e 14 anos" 4, Gardner, naturalista escocês que esteve no Brasil entre 1836 e

1 GOREnder.J. O escravismo colonial. $5^{\circ}$ ed., São Paulo: Ática, 1988 . p.321. MAtTOSO, K,. Ser escravo no Brasil. São Paulo: Brasiliense, 1982. p. 47.

3 MANNIX, D.P. \& Cowley, M.. Historia de ; a trata de negros; trad, de B. Rodrigues. $2^{\circ}$ ed. Madrid: Aliança Editorial, 1970. p. 47.

4 EBEL, E.. O Rio de Janeiro e seus arredores em 1824; trad, de J.S. Leão $\mathrm{F}^{\circ}$. $2^{\circ}$ ed. São Paulo: Ed. Nacional, 1972. p. 42. 
R. História, São Paulo. 120. p.85-96, jan/jul.19899.

1841, visitou uma fazenda no interior fluminense onde havia 200 escravos: 70 eram empregados na lavoura e os demais em vários ofícios, como ferreiros, carpinteiros, etc. O proprietário havia comprado, então, cerca de 20 ne* grinhos, entre 10 e 15 anos de idade, que não falavam português ${ }^{5}$.

A vinda de crianças africanas para o Brasil foi uma constante no período em que perdurou o tráfico de escravos. O historiador Herbert Klein, afirma que as taxas de embarque de crianças africanas, para o Brasil, variaram entre $1 \%$ e $20 \%$, aliás como nas demais regiões de economia escravista ${ }^{6}$.

Se havia pouco interesse pela criação de escravos, qual a razão destas crianças terem sido trazidas da África sós, ou com suas mães, apesar das dificuldades de sobrevivência e do menor preço alcançado no mercado brasileiro?

A criança escrava tem sido vista, em geral, como um futuro trabalhador. Aquele ou aquela que vai substituir, repor a mão de obra adulta. Gostaria de chamar, aqui a atenção para a especificidade da situação da criança escrava, seja como mercadoria, seja como trabalhador e tentar desvincular um pouco a criança da sua imagem de trabalhador-do-futuro.

\section{A mercadoria}

Bernardo Guimarães, no seu romance Rosaura, a enjeitada, publicado pela primeira vez em 1883, refere-se a uma celibatária de "cinquenta e muitos anos", que devia "a pequena fortuna que possuia graças à herança de um irmão que, tendo morrido intestado, sem outros herdeiros ascendentes, descendentes, nem colaterais, a deixou senhora de uma boa dúzia de escravos de um e de outro sexo, moços e robustos todos". Os escravos homens, ela os vendeu logo, "alegando que na qualidade de mulher não podia governar homens". Ficou com "sete raparigas, crioulas e mulatas, todas no viço da idade, bem feitas e vistosas". Comprou uma quinta onde vendia aguardente, fumo, quitanda e dava pousada aos passageiros." Um lucro porém mais avultado lhe provinha das 7 escravas; há 12 ou 14 anos que lhe pertenciam

5 GARDNER, G. Viagem ao interior do Brasil; trad, de M. Amado, Belo Horizonte, Itatiaia. São Paulo: EDUSP, 1975. p. 240.

6 KLEIN, H.,A demografía do tráfico de escravos no Brasil- Estudos Econômicos, vol. 17, n. 2, p. 129-149, 1987. 
MOTT, Maria Lucie de Barros. Ser mãe: a escrava em face do aborto e do infanticídio.

essas escravas tinham lhe dado já umas 20 e tantas crias lindas e vistosas, as quais logo que chegavam à idade de 10 anos, a boa mulher tratava de vender pelo melhor preço que podia. Seu estabelecimento bem que poderia chamarse um viveiro de escravos".

Bernardo Guimarães ao se referir à senhora, afirma que parece que ela conhecia um "anexim", um provérbio, "egoístico e deshumano de nossos antepassados que dizia: crioulos, criá-los e vendê-los".

O menor preço da criança escrava tomava-a uma mercadoria acessível aos pequenos proprietários impossibilitados muitas vezes de investirem na compra do escravo adulto. Expilly, comerciante francês que esteve no Rio de Janeiro em 1853, diz em seu livro Le Brésil tel qu'il est, que os moleques e os negrinhos eram muitas vezes enviados a aprender algum ofício, segundo a sua aptidão, o que posteriormente trazia um bom lucro ao senhor. ${ }^{8}$

A vida de trabalho da criança escrava começava cedo. Nas descrições, c nos desenhos, gravuras e fotografias elaborados por estrangeiros, que estiveram no Brasil no século passado, é freqüente depararmos com relatos e ilustrações de meninas e meninos carregando bebês no colo. A parisiense Mme. Toussaint, que morou no Rio de Janeiro em 1851, se refere ao puerperio das escravas: após três semanas elas voltavam para os trabalhos na lavoura, enquanto o bebê ficava entregue a negras velhas ou a meninas de 6 a 7 anos.

Nem todas as propriedades rurais possuíam escravas ou escravos velhos e crianças disponíveis para o cuidado das crianças menores. Muitas vezes, desde pequenas, eram obrigadas a acompanharem suas mães ao campo e com elas compartilhavam vários trabalhos agrícolas: tiravam hervas daninhas, semeavam frutas, cuidavam dos animais domésticos. ${ }^{\mathrm{I} 0}$

Aos 7 ou 8 anos iniciava-se uma nova etapa na vida da criança escrava: passavam a trabalhar no serviço mais pesado e regular. Deixavam para trás as últimas "regalias" infantis, aqueles que viviam na casa do senhor passavam a desempenhar funções específicas para sua idade ou já eram treinados para funções que desempenhariam vida a fora. Maria Firmina dos Reis

7 GUIMARAES, B. Rosaura, a enfeitada. Rio de Janeiro: Ed. Zélio Valverde, 1944. p. 139-140.

8 EXPILly, C. Le Brésil, tel qu'il est. Paris: Dentue Editeur, 1862. p. 186.

9 TOUSSAINT-SANSON, A. Viagem de uma parisiense ao Brasil; trad, de AECC. Rio de Janeiro: Typ. Imp. e Const, de J. VILleneUVE L.C., 1883. p. 44.

10 Sobre cotidiano da criança escrava, ver: MOTT, M.L.B. A criança escrava na literatura de viágens. Cad. de Pesquisa, vol. 31, p. 57-68, 1979. 
R. História, São Paulo. 120. p.85-96, jan/jul.1989

(1825-1917), escritora mulata, natural do Maranhão, no conto A escrava, publicado em 1887, narra a vida de uma escrava cafusa que começara a trabalhar aos 7 anos: "Joana que vá para o serviço, já tem 7 anos, e eu não admito escrava vadia", lhe disse o senhor ${ }^{11}$.

As crianças que ficavam na "casa grande" eram empregadas no serviço particular do senhor e dos familiares deste, Faziam as vezes de pagem, de moleque-de-recados, ou criada; iam buscar o jornal ou o correio nas vilas e cidades da vizinhança; encilhavam os cavalos; arrumavam o quarto; ajudavam a vestir, desvestir e a banhar as pessoas da casa e os visitantes; engraxavam os sapatos; escovavam as roupas; serviam a mesa, espantavam mosquitos; balançavam a rede; abanavam o fogo; buscavam água no poço; limpavam a cozinha; faziam compras; levavam e traziam recados; carregavam pacotes, lenço, leque, vela, missal, guarda-chuva, guarda-sol, etc.

Nas fazendas, nos engenhos, nas chácaras e sítios, aos 8 anos, as crianças já eram enviadas às plantações, ou então beneficiavam café, descaroçavam algodão, descascavam e ralavam mandioca, fabricavam cestos e cordas, guiavam carro-de-boi, pastoreavam o gado.

As meninas eram enviadas para verdadeiras escolas de mucamas onde aprendiam a bordar, a costurar, a pentear, a fazer bonecas e até mesmo a escrever $^{12}$.

Os meninos eram mandados para aprender algum ofício mecânico: ferreiro, sapateiro, alfaiate, barbeiro, marceneiro, etc; ou treinados como caçadores e em entomología e botânica para acompanhar cientistas ${ }^{13}$. Os jornais

11 MORAIS Fo, N. Maria Firmina dos Reis, fragmentos de uma vida. Maranhão, s.c.p., s.d.p., s.p. Por volta dos 12 anos encerrava-se mais uma fase na vida do escravo, deixando, então, de pertencer ao mundo infantil. Sobre as idades do escravo, ver: MOTT, M.L.B. A criança escrava na literatura de viagens, op. cit.; e MATTOSO, K. O filho da escrava (em torno da lei do Ventre-Uvre). Revista Brasileira de História, v. 8, n. 16, p, 37-55,1988.

12 Sobre as escolas de mucamas, ver: ASSIS, Machado. O caso da vara, In: $M a-$ chado de Assis, seus 30 melhores contos. Rio de Janeiro: Aguilar, 1961. p. 393 402; e MACEDO, J.M. Lucinda, a mucama. In: Victimas-Algozes. Rio de Janeiro; Typ. Americana, 1869. 2v.

13 Gostaria de ressaltar que há indicações de que nem sempre houve uma rígida divisão sexual do trabalho escravo infantil. Lembro aqui a pequena autobiografia de Luis Gama, onde ele se refere, aos trabalhos que executou quando permaneceu na casa de um traficante de escravos em Campinas. Ai, aprendeu a ser copeiro, sapateiro, a lavar, engomar e a costurar. In: GAMA, L. Obras completas. São Paulo: Edições Cultura, 1944. 
MOTT, Maria Lucie de Barros. Ser mãe: a escrava em face do aborto e do infanticídio.

das primeiras décadas do século XIX estampam anúncios de "professoras e professores" especializados em ensinar escravos. Na Gazeta do Rio de Janeiro, em 9 de julho de 1814, um morador da Rua do Lavradio oferceia-se para ensinar a ler, escrever, contar, etc. a quem quiser mandar as suas filhas, as suas crias e escravas ${ }^{14}$.

As crianças escravas eram também ocupadas na diversão de seus proprietários, quando eram obrigadas a brincar com os "sinhôzinhos", ou então tocavam algum instrumento para platéia selecionada.

O valor econômico, nem mesmo a pouca idade, livrou as crianças escravas dos maus tratos: eram castigados, separados de seus familiares, trabalhavam duro, ficando muitas vezes corn marcas físicas dos castigos e do excesso de trabalho, para o resto da vida $1^{5}$.

Os anúncios de jornais sobre fuga de escravos, coletados por Gilberto Freire, são prôdigos em apresentar meninos de 10, 11 anos, com falhas no cabelo por carregarem vários tipos de mercadorias na cabeça, com as mãos calejadas, marcas de relho, parte do corpo queimadas devidos aos castigos 16 .

A crença na inocência da infância parece ter refletido na maneira de alguns proprietários tratarem as crianças escravas. Determinadas promessas feitas por adulto, por exemplo, acreditava-se que só teriam valor se realizadas por crianças. Também eram elas que deveriam - pela suposta pureza carregar determinados objetos utilizados nos cultos religiosos.

Até os 7 ou 8 anos, algumas crianças escravas parecem ter gozado de algumas "regalias" que Debret ironizou como sendo semelhante àquela recebida pelos animais domésticos ${ }^{17}$. Sirneão. o Crioulo, personagem da tri-

14 Citado por LUCCOCK, J.. Notas sobre o Ma de. Janeiro (...); trad, de M.S. Rodrigues. Belo Horizonte; Etatiaia; São Paulo: EDUSP, 1975. p. 567.

15 José Bonifácio de Andrada e Silva, elaborou um projeto de Lei sobre a emancipação gradual dos escravos, em 1823, onde apresenta alguns artigos sobre o tratamento que deveria ser dispensado à família escrava. O artigo 16, regulamenta o trabalho infantil: "Antes dos 12 anos não deverão os escravos ser empregados em trabalhos insalubres e demasiados; e o conselho vigiará sobre a execução deste artigo para bem do Estado e tios mesmos senhores". In:MALHEIRO, Perdigão. A escravidão no Brasil. 3" ed. Petrópolis: Vozes; Brasilia: INL, 1976. p. 229, $2 \mathrm{v}$. Se o trabalho insalubre mereceria ser regulamentado por lei, acredito que é porque, na prática, muitas crianças com menos de 12 anos, aí já trabalhavam.

16 FREIRE, G. O escravo nos anúncios de jornais no séc. XIX. São Paulo: Ed. Nacional, 1979.

17 DEBRET, J.B. Viagem pitoresca e histórica ao Brasil: trad, de S. Milliet. Belo Horizonte, Itatiaia; São Paulo: EDUSP, 1978. p. 195, v. 1. 
logia Victimas-Algozes, de Joaquim Manuel de Macedo, "tinha prato à mesa e leito no quarto de seus senhores até os 8 anos", sendo depois desta idade"' privado do quarto e da mesa em comum $1^{8}$.

Mme. Durocher, parteira por cerca de 50 anos no Rio de Janeiro, afirma que as crias em geral eram transformadas em tetéias por causa da sua pouca idade e ignoravam a distância respeitosa que deveria haver entre seu senhor, que as vezes tinha mais ou menos a mesma idade. Quando estas crias se rebelavam contra as mordidas e tiranias sofridas, os pais em vez de reprenderem os filhos, acabavam por castigar o pequeno escravo cujo único crime, freqüentemente era fugir do "sinhôzinho" e não deixar que ele o mordesse à vontade. Ainda é a parteira quem conta o caso ocorrido numa escola do Rio de Janeiro, onde um fazendeiro levara um "moleque" à escola para que recebesse no lugar deste, os castigos que viesse a merecer ${ }^{19}$.

Esses fatos relatados pela parteira que podem soar como piada de mau gosto nos dias de hoje, merecem ser levados em consideração, pois existem outros exemplos na literatura médica que servem como termômetro para medír a relação entre o senhor e a criança escrava: em 1804, negociantes da Bahia, sob o patrocínio do futuro marquês de Barbacena, fizeram com que fossem mandadas 7 crianças escravas para Lisboa, acompanhadas de um cirurgião, para trazerem de lá o pus vacínico da varíola. Durante a viagem de volta pelo Atlântico foram sendo inoculados um a um, de braço a braço, os pequenos negros, conseguindo assim trazer para o Brasil, o pus destinado à vacinação ${ }^{20}$.

Assim, acredito, que o valor econômico da criança escrava não pode ser desprezado. Não pretendo, aqui, negar a lógica de muitos proprietários de que, em algumas épocas e em determinadas regiões, preferiam o escravo do sexo masculino em idade adulta, e pouca importância davam à prole escrava.

Não se pode negar, porém que houve um lugar para a criança escrava no sistema escravista, seja pelo menor preço que tinha no mercado, o que possibilitava que fosse adquirida por pessoa de menos posses; seja pelas múltiplas e variadas funções que desempenhou. Funções estas, vale a pena lembrar, com características específicas, e algumas delas dificilmente realizadas por outrem.

\footnotetext{
18 MACEDO, J.M.Simeão, o crioulo. In: Victimas-Algozes, op. cit.

19 DURỌCHER, M.J.M.. Idéias por coordenar a respeito da emancipação dos escravoa. Rio de Janeiro: Typ. do Diário do Rio de Janeiro, 1871. pp. 6-7.

20 SANTOS Fo L. História da Medicina no Brasil, São Paulo: Brasiliense, 1947.
} 
MOTT, Maria Lucie de Barros. Ser mãe: a escrava em face do aborto e do infanticídio.

A criança escrava, por exemplo, foi muitas vezes, empregada no lugar do adulto, quando trabalhava como vendedor ou no pastoreio. Outras vezes, seu trabalho era complementar ao do adulto, quando ajudava a colher café, descaroçar algodão, catar lenha. Este tipo de atividade, apesar dos benefícios que o adulto usufruía, não era considerado, nem os lucros contabilizados.

A criança escrava foi obrigada, também, a executar um tipo de atividade que pode ser considerada como suporte para o trabalho adulto, liberandoo assim de certas tarefas. As meninas ocupadas em pajear as crianças menores, ou os meninos que iam buscar água no poço, são um exemplo. Este trabalho, em geral também permanece invisível.

Houve, ainda, um tipo de função que, muitas vezes, só a criança escrava pode desempenhar: era quando servia de brinquedo e divertimento para os proprietários, ou era obrigada a executar cerimônias ligadas ao culto religioso.

Houve, porém, um tipo de função que apenas a criança escrava desempenhou: foi quando gerou e preservou o leite de sua mãe. Daí talvez a razão das crianças acompanharem suas mães nos navios negreiros, $\mathrm{O}$ bebê, ou a cria-de-peito, dava um qualificativo à escrava: o de ama-de-leite.

Acredito que todos estes aspectos devem ser levados em conta quando se fala da pouca importância que o escravismo dava à criança escrava e à ausência do significado de resistência das práticas abortivas e infanticidas.

Mesmo que não fosse peto valor econômico da criança escrava, como mercadoria ou como trabalhador, e aborto impediria a escrava de dar o leite à prole do senhor. A literatura do século XIX aconselhava às senhoras, que amaraentassem elas próprias seus filhos, pois as escravas eram acusadas de certas práticas, realizadas com o intuito de prejudicar a amamentação dos bebês proprietários, como colocar pimenta no bico do seio, dar paninhos para que chupassem e não reclamassem de fome ${ }^{21} 21$.

$\mathrm{O}$ argumento de que as escravas praticavam o aborto e o infanticidio para livrar seus filhos do cativeiro reduz ao meu ver a questão. $E$ um argumento, diria, moralmente aceito, válido e justificável, que pode ser encontrado desde o final do sécuto XVÍí e início do século XVIII. Antonil aconselhava que os proprietários tratassem bem seus escravos para que eles ficassem felizes e assim reproduzissem servos e servas. Caso contrário, algumas

21 Sobre amas-de-leite, ver: MAGALHÃES, E.K.C. e GIACOMINI, S.M. A escrava ama-de-leite: anjo ou demônio? In: BARROSO, C. \& COSTA, A.O. Mulher, Mulheres. São Paulo; Cortez, Fundação Carlos Chagas, 1983. p. 73-88. 
negras procuravam de propósito o aborto, só para seus filhos não padecerem o que elas padeciam ${ }^{22}$.

O mesmo discurso foi utilizado pelo Reverendo Walsh, que visitou o Brasil nas primeiras décadas do século $\mathrm{XIX}^{23}$; e pelo jurista Perdigão MaIheiro, no seu livro A escravidão no Brasl, publicado em $1866^{24}$.

Castro Alves tem uma emocionada poesia, chamada Mater Dolorosa, incluída no seu livro Os escravos, onde se refere ao aborto das escravas, como um ato de amor ${ }^{25}$.

"Meu filho, dorme, dorme o sono eterno

No berço esplêndido que se chama - o céu

Pede às estrelas um olhar materno,

Um seio quente como o seio meu.

Ai! borboleta na gentil crisálida,

Asas de ouro vai além abrir

Ai ! rosa branca no matiz tão pálida

Longe, tão longe vai além florir.

(...)

Não me maldigas...Num amor sem termo

Bebi a força de matar-te...a mim ...

Viva eu cativa a soluçar num ermo...

Filho, se livre... sou feliz assim...

$$
\text { (...) }
$$

Perdão meu filho...se matar-te é crime...

Deus me perdoa... me perdoa já.

A fera enchente quebraria o vime...

Valem-te os anjos e te cuidem lá.

$$
\text { (...)" }
$$

No romance Motta Coqueiro, do também abolicionista José do Patrocínio, a escrava Carolina, grávida do feitor, quando se viu preterida, procurou a escrava Balbina, tida como feiticeira:

22 Antonil, pseud. de Andreoni. Cultura e opulência no Brasil. 2 ed. São Paulo: Ed. Nacional, s.d. p. 164.

23 WALSH, Rev. Notices of Brazil (...) LONDON, F. Wentley \&. DAVIS, H.H., 1830. p. 349, 2v.

24 MAlHe1RO, P. A escravidão no Brasil v. 2, p. 34,p, 34, v. 2.

25 Alves, C. Os escravos. São Paulo: Livraria Martins Ed., 1976. p. 53. 
MOTT, Maria Lucie de Barros. Ser mãe: a escrava em face do aborto e do infanticídio.

"- Você sabe que eu estou pejada (...) falou Carolina.

- Balbina sabe de tudo (...)

- Mas eu não quero sofrer assim tia Balbina, não quero dar o peito ao filho de Manuel João (...)

- Bico! disse a feiticeira; levantando o dedo aos lábios. Você está

dizendo pecado. Escute primeiro a voz do chocalho de Balbina."

E o chocalho responde: "que o filho de Carolina tem que sofrer o cativeiro do mau senhor. Brancos podem surrar, podem vender o filho da sua escrava, e a escrava há de tomar ogirisa dos brancos. Antes o filho não nasÇ», se há de passar tantos trabalhos, antes vá para os anjos no taboleiro com rosas e girassóis" 26

É pecado não dar o peito ao filho, mas não é pecado livrar o filho do cativeiro, das mãos do mau senhor.

Concluindo: a recusa da escrava em repor a mão de obra, seja pelo reconhecimento do valor da sua prole como mercadoria, seja por não desejar dar o seio, o alimento ao Filho do senhor, ou ainda para que seu filho não sofresse o cativeiro, são algumas das leituras possíveis do aborto e infanticidio como formas de resistência.

Existem outras, como a recusa da escrava em ter filhos mulatos, fruto da violência sexual, ou também em ver aumentada com a maternidade, os seus inúmeros trabalhos e já pesados encargos. Apesar de ser hábito $\mathrm{cm}$ algumas regiões da África as mulheres carregarem seus filhos na costa enquanto trabalham, isto restringe-se a algumas horas por dia. No Brasil tal prática foi levada ao extremo, o que chegou a acarretar transformações no corpo das crianças. Estas são algumas das questões que eu gostaria de trazer para o debate.

ABSTRACT: The author studies children slavery, through a critical survey of contemporary historiography and documenta their presence in 19 th century Brazil. Starting from numbers, estimates that they represented 1 to $20 \%$ of the total slave population. The author reconstitutes their lives and their work activities from 7 to 12 years old. Refers to physical deformation caused by specific activities, the habit of sending them to schools to be trained for certain jobs, the exploitation of their mothers as breastfeeders. Revises the notion of their economic value. Finally, discusses abortion practices as strategies of resistance.

UNITERMS : children slaves, child labor, abortion, infanticide.

26 Patrocinio, J.. Motta Coqueiro. Rio de Janeiro: Império, s.d. p. 57-58. 
R. História, São Paulo. 120. p.85-96, jan/jul.1989

\section{REFERÊNCIAS BIBLIOGRÁFICAS}

ALVES, C.

1947 Os escravos. São Paulo: Martins.

ASSIS, M.

1961 O caso da vara. Machado de Assis, seus 30 melhores contos. Rio de Janeiro: Aguilar, p. 393-402.

ANDREONI, J.A. (peeud. Antonil).

a.d. Cultura e opulência do Brasl $2^{\circ}$ ed. São Paulo: Nacional.

DEBRET, J.B.

1978 Viagem pitoresca e histórica ao Brasil. Belo Horizonte: Itatiaia; São Paulo: EDUSP.

DUROCHER, M.J.M.

1871 idéias por coordenar a respeito da emancipação. Rio de Janeiro: Typ. do Diário do Rio de Janeiro.

EXP1LLY, C.

1862 Le Brésil tel qu'il est. Paris, Detitue Éditeur.

EBEL. E.

1972 O Rio de Janeiro e seus arredores em 1824; trad, de J. de Sou/a Leão F ${ }^{\circ} ; 2^{\circ}$ ed. São Paulo: Nacional.

FREIRE, G.

1979 O escravo nos anúncios dos jornais do século XIX. São Paulo: Nacional.

GAMA, L.

1944 Obras completas. São Paulo: Cultura.

GARDNER, G.

1975 Viagem ao interior do Brasil: trad, de M. Amado, líelo Horizonte: Itatiaia; São Paulo; BDUSP.

\section{GORBNDER.J.}

$1988 O$ escravismo colonial. $5^{\text {a }}$ ed. São Paulo: Ática.

GUIMARÃES, 8.

1944 Rosaura, a enfeitada. Rio de Janeiro: Zélio Valverde. 
MOTT, Maria Lucie de Barros. Ser mãe: a escrava em face do aborto e do infanticídio.

KLEIN, H.

1987 A demografía do tráfico de escravos para o Brasil. Estudos Econômicos, v. 17, n. 2, p. 129-149.

\section{LUCCOCK.J.}

1975 Notas sobre o Rio de Janeiro (...); trad, de M. da S. Rodrigues. Belo Horizonte: Itatiaia; São Paulo: EDUSP.

\section{MACEDO, J.M.}

1869 Victimas-Algozes. Rio de Janeiro: Typ. Americana.

MAGALHÃES,E.K.C. \& GIACOMINI, S.M.

1983 A escrava ama-de-leíte: anjo ou demônio? In: BARROSO, C. \& COSTA, A.O. Mulher, mulheres. São Paulo: Cortez, Fundação Carlos Chagas, p. 73-88.

MALHEIRO, P.

1976 A escravidão no Brasil. $3^{\circ}$ ed. Petrópolis, Vozes; Brasília; INL, 2 v.

MANNIX, D.P. \& COWLEY, M.

1970 História de Ia trata de negros; trad, de E.B. Rodrigues, Madrid: Alianza Editorial.

MATTOSO, K.

1988 O filho da escrava (em tomo de lei do Ventre-Livre). Revista Brasileira de História, v. 8, n. 16, p. 37-55.

1982 Ser escravo no Brasil. São Paulo: Brasiliense.

MORAIS F?, N.

s.d. Maria Firmina dos Reis, fragmentos de uma vida. Maranhão: s.c.p.

MOTT, M.L.B.

1979 Criança escrava na literatura de viagens. Cadernos de Pesquisa, n. 31, p. 5767 , dez.

PATROCÍNIO, J.

s.d. Moita Coqueiro. Rio de Janeiro: Império.

SANTOS $\mathrm{F}^{\circ}, \mathrm{L}$.

1947 História da Medicina no Brasil. São Paulo: Brasiliense, 2 v.

TOUSSAINT-SANSON, A.

1883 Viagem de uma parisiense ao Brasl; trad, de AECC. Rio de Janeiro: Typ. Imp. e Const, de J. Villeneuve L.C.

WALSH, R.

1830 Notices of Brazil. 2 vols. London: F. Westley \& H,H, Davis. 